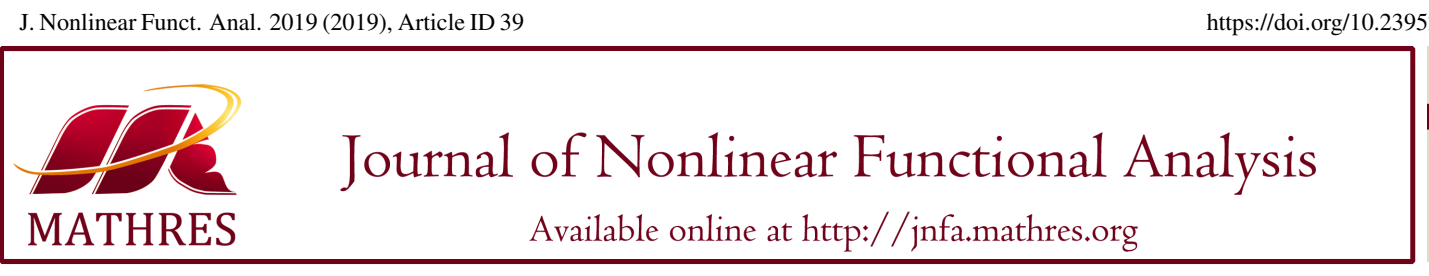

https://doi.org/10.23952/jnfa.2019.39

\title{
SEVERAL ITERATIVE ALGORITHMS FOR SOLVING THE MULTIPLE-SET SPLIT COMMON FIXED-POINT PROBLEM OF AVERAGED OPERATORS
}

\author{
JING ZHAO*, DINGFANG HOU, HAILI ZONG \\ College of Science, Civil Aviation University of China, Tianjin 300300, China
}

\begin{abstract}
In this paper, we use the dual variable to propose a new cyclic iterative algorithm for solving the multiple-set split common fixed-point problem of averaged operators in Hilbert spaces. Inspired by the idea of parallel iterative algorithms, we also introduce two mixed iterative algorithms which combine the process of cyclic and parallel together. Under mild assumptions, we prove weak convergence of the proposed iterative sequences in Hilbert spaces. As applications, we obtain several iterative algorithms to solve the multiple-set split feasibility problem.
\end{abstract}

Keywords. Multiple-set split common fixed point problem; Multiple-set split feasibility problem; Averaged operators; Weak convergence; Iterative algorithms.

2010 Mathematics Subject Classification. 47H05, 47H09, 47J05, 90C25.

\section{INTRODUCTION}

The multiple-set split feasibility problem (MSFP), first introduced by Censor et al in [1], is a general way to characterize various linear inverse problems which arise in many real-world problems, such as, medical image reconstruction [2] and intensity-modulated radiation therapy [3,4]. The multiple-set split feasibility problem is required to find a point in the intersection of a family of nonempty closed convex subsets in one space such that its image under a certain operator is in the intersection of another family of nonempty closed convex subsets in the image space. Let $H_{1}$ and $H_{2}$ be real Hilbert spaces and let $A: H_{1} \rightarrow H_{2}$ be a bounded linear operator. Given integers $p, r \geq 1$, the MSFP is formulated as finding a point $x^{*}$ satisfying the property:

$$
x^{*} \in \bigcap_{i=1}^{p} C_{i} \text { such that } A x^{*} \in \bigcap_{j=1}^{r} Q_{j},
$$

where $\left\{C_{i}\right\}_{i=1}^{p}$ and $\left\{Q_{j}\right\}_{j=1}^{r}$ are nonempty closed convex subsets of $H_{1}$ and $H_{2}$, respectively.

${ }^{*}$ Corresponding author.

E-mail addresses: zhaojing200103@163.com (J. Zhao), hdfjiayou@icloud.com (D. Hou), 861350555@ qq.com (H. Zong).

Received September 20, 2018; Accepted July 22, 2019. 
The MSFP (1.1) with $p=r=1$ is known as the split feasibility problem (SFP) originally introduced by Censor and Elfving [5] which is formulated as finding a point $x^{*}$ satisfying the property:

$$
x^{*} \in C \text { such that } A x^{*} \in Q,
$$

where $C$ and $Q$ are nonempty closed convex subset of $H_{1}$ and $H_{2}$, respectively. The iterative methods for solving the SFP and MSFP have been paid much attention in recent years.

Note that, if the SFP (1.2) is consistent (i.e., it has a solution), the SFP (1.2) can be formulated as a fixed point equation by using the fact

$$
P_{C}\left(I-\gamma A^{*}\left(I-P_{Q}\right) A\right) x^{*}=x^{*}
$$

where $P_{C}$ and $P_{Q}$ are the (orthogonal) projections onto $C$ and $Q$, respectively, $\gamma>0$ is any positive constant and $A^{*}$ denotes the adjoint of $A$. That is, $x^{*}$ solves the SFP (1.2) if and only if $x^{*}$ solves the fixed point equation (1.3) (see [6] for the details). This implies that we can use fixed point algorithms (see $[7,8,9,10,11,12,13,14])$ to solve the SFP. Byrne $[15,16]$ proposed the so-called CQ algorithm which generates a sequence $\left\{x_{k}\right\}$ by

$$
x_{k+1}=P_{C}\left(x_{k}-\gamma A^{*}\left(I-P_{Q}\right) A x_{k}\right),
$$

where $\gamma \in(0,2 / \lambda)$ with $\lambda$ being the spectral radius of the operator $A^{*} A$. The $\mathrm{CQ}$ algorithm only involves the computations of the projections $P_{C}$ and $P_{Q}$ onto the sets $C$ and $Q$, respectively, and is therefore implementable in the case where $P_{C}$ and $P_{Q}$ have closed-form expressions.

Since every closed convex subset of a Hilbert space is the fixed point set of its associated projection, problems (1.1) and (1.2) are special cases of the so-called multiple-set split common fixed-point problem (MSCFP). Let $p, r \geq 1$ be integers, $\left\{U_{i}\right\}_{i=1}^{p}: H_{1} \rightarrow H_{1}$ and $\left\{T_{j}\right\}_{j=1}^{r}: H_{2} \rightarrow H_{2}$ be nonlinear operators and $A: H_{1} \rightarrow H_{2}$ be a bounded linear operator. The MSCFP can be formulated as the problem of finding

$$
x^{*} \in \bigcap_{i=1}^{p} F\left(U_{i}\right) \text { such that } A x^{*} \in \bigcap_{j=1}^{r} F\left(T_{j}\right),
$$

where, for $1 \leq i \leq p$ and $1 \leq j \leq r, F\left(U_{i}\right)$ and $F\left(T_{j}\right)$ stand for the fixed point sets of $U_{i}: H_{1} \rightarrow H_{1}$ and $T_{j}: H_{2} \rightarrow H_{2}$, respectively. In particular, if $p=r=1$, then MSCFP (1.5) is reduced to finding a point $x^{*}$ with the property:

$$
x^{*} \in F(U) \text { such that } A x^{*} \in F(T),
$$

which is usually called the split common fixed-point problem (SCFP). The concept of the SCFP in finite-dimensional Hilbert spaces was originally introduced by Censor and Segal [17] who proposed and proved, in finite-dimensional spaces, the convergence of the following algorithm for the SCFP of directed operator with nonempty fixed point sets:

$$
x_{k+1}=U\left(x_{k}+\gamma A^{t}(T-I) A x_{k}\right), \quad k \in N,
$$

where $\gamma \in\left(0, \frac{2}{\lambda}\right)$ with $\lambda$ being the largest eigenvalue of the matrix $A^{t} A\left(A^{t}\right.$ stands for matrix transposition). Some authors have introduced some algorithms to solve SCFP (1.2) (see [18, 19, 20, 21]).

Many iterative algorithms have been developed to solve the MSCFP and the MSFP. See, for example $[22,23,24,25,26,27,28,29,30]$ and references therein. For solving the constrained MSFP, Censor et. 
al. [1] introduced the proximity function:

$$
g(x):=\frac{1}{2} \sum_{i=1}^{p} \alpha_{i}\left\|x-P_{C_{i}} x\right\|^{2}+\frac{1}{2} \sum_{j=1}^{r} \beta_{j}\left\|A x-P_{Q_{j}}(A x)\right\|^{2},
$$

where $\alpha_{i}>0(1 \leq i \leq p), \beta_{j}>0(1 \leq j \leq r)$ and $\sum_{i=1}^{p} \alpha_{i}+\sum_{j=1}^{r} \beta_{j}=1$. Then

$$
\nabla g(x)=\sum_{i=1}^{p} \alpha_{i}\left(x-P_{C_{i}} x\right)+\sum_{j=1}^{r} \beta_{j} A^{*}\left(A x-P_{Q_{j}}(A x)\right)
$$

and they proposed the following projection method:

$$
x_{k+1}=P_{\Omega}\left(x_{k}-\gamma \nabla g\left(x_{k}\right)\right)
$$

where $\Omega$ is the constrained set, $0<\gamma_{L} \leq \gamma \leq \gamma_{U}<\frac{2}{L}$ and $L$ is the Lipschitz constant of $\nabla g$.

Wang and $\mathrm{Xu}$ [31] proposed the following cyclic iterative algorithm for the MSCFP (1.5) of directed operators:

$$
x_{k+1}=U_{[k]_{1}}\left(x_{k}+\gamma A^{*}\left(T_{[k]_{2}}-I\right) A x_{k}\right),
$$

where $0<\gamma<2 / \rho\left(A^{*} A\right),[k]_{1}:=k(\bmod p)$ and $[k]_{2}:=k(\bmod r)$. They proved the weak convergence of the sequence $\left\{x_{k}\right\}$ generated by (1.9).

Assume that $\left\{\omega_{i}\right\}_{i=1}^{p} \subset(0,1),\left\{\eta_{j}\right\}_{j=1}^{r} \subset(0,1)$ with $\sum_{i=1}^{p} \omega_{i}=1$ and $\sum_{j=1}^{r} \eta_{j}=1$, and $\lambda=\rho\left(A^{*} A\right)$, $0<a \leq \gamma_{k} \leq b<2 / \lambda$. For solving the MSCFP (1.5) of directed operators, Tang and Liu [32] introduced the parallel iterative algorithm by the following way:

$$
x_{k+1}=\sum_{i=1}^{p} \omega_{i} U_{i}\left(x_{k}+\gamma_{k} \sum_{j=1}^{r} \eta_{j} A^{*}\left(T_{j}-I\right) A x_{k}\right) .
$$

They also proposed inner parallel and outer cyclic iterative algorithm:

$$
x_{k+1}=U_{[k]_{1}}\left(x_{k}+\gamma_{k} \sum_{j=1}^{r} \eta_{j} A^{*}\left(T_{j}-I\right) A x_{k}\right)
$$

and outer parallel and inner cyclic iterative algorithm:

$$
x_{k+1}=\sum_{i=1}^{p} \omega_{i} U_{i}\left(x_{k}+\gamma_{k} A^{*}\left(T_{[k]_{2}}-I\right) A x_{k}\right),
$$

where $[k]_{1}=k(\bmod p)$ and $[k]_{2}=k(\bmod r)$. They obtained the weak convergence of the above three iterative sequences to solve the MSCFP (1.5) of directed operators.

In this paper, we use the dual variable to propose several iterative algorithms for solving the MSCFP (1.5) governed by averaged operators. In [33], Chen, Huang and Zhang designed and discussed an efficient algorithm framework for minimizing the sum of two proper lower semi-continuous convex functions, i.e.,

$$
x^{*}=\arg \min _{x \in R^{n}} f_{1}(x)+f_{2}(x),
$$

where $f_{1}, f_{2} \in \Gamma_{0}\left(\mathbb{R}^{n}\right)$ (all proper lower semi-continuous convex functions from $\mathbb{R}^{n}$ to $(-\infty,+\infty]$ ) and $f_{2}$ is differentiable on $R^{n}$ with $1 / \beta$-Lipschitz continuous gradient for some $\beta \in(0,+\infty)$. To solve convex 
separable problem (1.11), they obtained the following fixed point formulation: the point $x^{*}$ is a solution of (1.11) if and only if there exists $v^{*} \in \mathbb{R}^{n}$ such that

$$
\left\{\begin{array}{l}
v^{*}=\left(I-\operatorname{prox}_{\frac{\gamma}{\lambda} f_{1}}\right)\left(x^{*}-\gamma \nabla f_{2}\left(x^{*}\right)+(1-\lambda) v^{*}\right), \\
x^{*}=x^{*}-\gamma \nabla f_{2}(x)-\lambda v^{*}
\end{array}\right.
$$

where $\lambda$ and $\gamma$ are two positive numbers. They introduced the following Picard iterative sequence:

$$
\left\{\begin{array}{l}
v_{k+1}=\left(I-\operatorname{prox}_{\frac{\gamma}{\lambda} f_{1}}\right)\left(\left(x_{k}-\gamma \nabla f_{2}\left(x_{k}\right)\right)+(1-\lambda) v_{k}\right), \\
x_{k+1}=x_{k}-\gamma \nabla f_{2}\left(x_{k}\right)-\lambda v_{k+1} .
\end{array}\right.
$$

It was shown [33] that under appropriate conditions $\left\{x_{k}\right\}$ converges to a solution of problem (1.11). Since $x$ is the primal variable related to (1.11), it is very natural to ask what role the variable $v$ plays in above algorithm. After a thorough study, they found out that $v$ is actually the dual variable of the primal-dual form related to (1.11).

Motivated by [33], by optimization approach, Zhao and Zong [34] proposed the following algorithm to solve SFP (1.2)

$$
\left\{\begin{array}{l}
y_{k}=x_{k}-\gamma_{k} A^{*}\left(I-P_{Q}\right) A x_{k}, \\
v_{k+1}=\left(I-P_{C}\right)\left(y_{k}+(1-\lambda) v_{k}\right), \\
x_{k+1}=y_{k}-\lambda v_{k+1},
\end{array}\right.
$$

where $0<\liminf _{k \rightarrow \infty} \gamma_{k} \leq \limsup \operatorname{sum}_{k \rightarrow \infty} \gamma_{k}<\frac{2}{\|A\|^{2}}$ and $0<\lambda \leq 1$. When $\lambda=1$, algorithm (1.13) becomes the CQ algorithm (1.6). They obtained that the sequence $\left\{x_{k}\right\}$ weakly converges to a solution of SFP (1.2).

Inspired and motivated by the works mentioned above, we use the dual variable to propose a new cyclic iterative algorithm for MSCFP (1.5) governed by averaged operators. We also propose two mixed iterative algorithms which combine the process of cyclic and parallel iteration together. As applications, we obtain several iterative algorithms to solve MSFP (1.1).

The contents of this paper are as follows. First, we give some useful definitions and results for the convergence analysis of the iterative algorithms in next section. Second, we prove weak convergence theorems of the proposed cyclic iterative algorithm with the dual variable. Finally, we prove weak convergence theorems of two mixed iterative algorithms.

\section{PRELIMINARIES}

Next, we denote the inner product by $\langle\cdot, \cdot\rangle$ and the norm by $\|\cdot\|$. Let $I$ denote the identity operator on Hilbert space $H$. We denote the fixed point set of an operator $T$ by $F(T)$. We denote by $\rightarrow$ the strong convergence and by $\rightarrow$ the weak convergence, respectively. We use $\omega_{w}\left(x_{k}\right)=\left\{x: \exists x_{k_{j}} \rightarrow x\right\}$ stand for the weak $\omega$-limit set of $\left\{x_{k}\right\}$.

Definition 2.1. An operator $T: H \rightarrow H$ is said to be

(i) nonexpansive if $\|T x-T y\| \leq\|x-y\|$ for all $x, y \in H$,

(ii) firmly nonexpansive if $2 T-I$ is nonexpansive or, equivalently, for all $x, y \in H$,

$$
\|T x-T y\|^{2} \leq\|x-y\|^{2}-\|(x-y)-(T x-T y)\|^{2},
$$


(iii) firmly quasi-nonexpansive (also directed) if $F(T) \neq \emptyset$ and

$$
\langle x-q, T x-q\rangle \geq\|T x-q\|^{2}, \forall x \in H, \forall q \in F(T)
$$

or, equivalently,

$$
\|T x-q\|^{2} \leq\|x-q\|^{2}-\|x-T x\|^{2}, \forall x \in H, \forall q \in F(T) .
$$

Definition 2.2. An operator $T: H \rightarrow H$ is said to be an averaged operator if it can be written as the average of $I$ and a nonexpansive operator, that is,

$$
T=(1-\alpha) I+\alpha S,
$$

where $\alpha$ is a number in $(0,1)$ and $S: H \rightarrow H$ is nonexpansive. More precisely, when the above equality holds, we say that $T$ is $\alpha$-averaged.

Remark 2.3. $T$ is $\alpha$-averaged if and only if the following inequality holds:

$$
\|T x-T y\|^{2} \leq\|x-y\|^{2}-\frac{1-\alpha}{\alpha}\|(I-T) x-(I-T) y\|^{2}
$$

for all $x, y \in H$.

Definition 2.4. An operator $T: H \rightarrow H$ is called demiclosed at the origin if, for any sequence $\left\{x_{n}\right\}$ which weakly converges to $x$, and if the sequence $\left\{T x_{n}\right\}$ strongly converges to 0 , then $T x=0$.

Definition 2.5. Given a number $\alpha>0, T: H \rightarrow H$ is said to be $\alpha$-inverse strongly monotone $(\alpha$-ism) if

$$
\langle x-y, T x-T y\rangle \geq \alpha\|T x-T y\|^{2}, \forall x, y \in H .
$$

Recall that the metric projection from $H$ onto a nonempty closed convex subset $C$ of $H$, denoted by $P_{C}$, is defined as follows: for each $x \in H$,

$$
P_{C}(x)=\arg \min _{y \in C}\{\|x-y\|\} .
$$

It is well known that $P_{C} x$ is characterized by the inequality:

$$
P_{C} x \in C,\left\langle x-P_{C} x, z-P_{C} x\right\rangle \leq 0, z \in C .
$$

The following lemmas will be helpful for the convergence analysis of the proposed iterative algorithms.

Lemma 2.6. Let $H$ be a real Hilbert space. Then

$$
2\langle x, y\rangle=\|x\|^{2}+\|y\|^{2}-\|x-y\|^{2}=\|x+y\|^{2}-\|x\|^{2}-\|y\|^{2}, \forall x, y \in H .
$$

Lemma 2.7. [35] Let $H$ be a real Hilbert space. Then for all $t \in[0,1]$ and $x, y \in H$,

$$
\|t x+(1-t) y\|^{2}=t\|x\|^{2}+(1-t)\|y\|^{2}-t(1-t)\|x-y\|^{2} .
$$

Lemma 2.8. [36] Let $H$ be a real Hilbert space. Then

$$
\left\|\alpha_{0} x_{0}+\alpha_{1} x_{1}+\alpha_{2} x_{2}+\alpha_{3} x_{3}+\cdots+\alpha_{r} x_{r}\right\|^{2} \leq \Sigma_{i=0}^{r} \alpha_{i}\left\|x_{i}\right\|^{2}-\alpha_{s} \alpha_{t}\left\|x_{s}-x_{t}\right\|^{2}
$$

for any $s, t \in\{0,1,2, \cdots, r\}$ and for $x_{i} \in H, i=0,1,2, \cdots, r$ with $\alpha_{0}+\alpha_{1}+\cdots+\alpha_{r}=1$ and $0 \leq \alpha_{i} \leq 1$.

Lemma 2.9. [16] $T$ is averaged if and only if the complement $I-T$ is $v$-ism for some $v>\frac{1}{2}$. Indeed, for $\alpha \in(0,1), T$ is $\alpha$-averaged if and only if $I-T$ is $\frac{1}{2 \alpha}$-ism. 
Lemma 2.10. [6] Let $K$ be a nonempty closed convex subset of real Hilbert space $H$. Let $\left\{x_{k}\right\}$ be a bounded sequence which satisfies the following properties:

(i) every weak limit point of $\left\{x_{k}\right\}$ lies in $K$;

(ii) $\lim _{k \rightarrow \infty}\left\|x_{k}-x\right\|$ exists for every $x \in K$.

Then $\left\{x_{k}\right\}$ converges weakly to a point in $K$.

Lemma 2.11. [37] Let E be a uniformly convex Banach space, $K$ be a nonempty closed convex subset of $E$ and $T: K \rightarrow K$ be a nonexpansive mapping. Then $I-T$ is demi-closed at origin.

\section{THE CYCLIC ITERATIVE ALGORITHM}

In this section, we introduce a new cyclic iterative algorithm and prove the weak convergence for solving the MSCFP (1.5) of averaged operators with the dual variable.

In what follows, we adopt the following assumptions:

(A1) $\Gamma$ denotes the solution set of the MSCFP (1.5) and $\Gamma$ is nonempty;

(A2) $U_{i}: H_{1} \rightarrow H_{1}(1 \leq i \leq p)$ is $s_{i}$-averaged operators and $T_{j}: H_{2} \rightarrow H_{2}(1 \leq j \leq r)$ is $t_{j}$-averaged operators, $s=\max \left\{s_{i}: 1 \leq i \leq p\right\}$ and $t=\max \left\{t_{j}: 1 \leq j \leq r\right\}$;

(A3) $\forall k \geq 0, j(k)=k(\bmod r)+1, i(k)=k(\bmod p)+1$.

Algorithm 3.1. Let $x_{0}, v_{0} \in H_{1}$ be arbitrary. For $k \geq 0$, let

$$
\left\{\begin{array}{l}
y_{k}=x_{k}-\gamma_{k} A^{*}\left(I-T_{j(k)}\right) A x_{k}, \\
v_{k+1}=\left(I-U_{i(k)}\right)\left(y_{k}+(1-\lambda) v_{k}\right), \\
x_{k+1}=y_{k}-\lambda v_{k+1}
\end{array}\right.
$$

where $\gamma_{k} \in\left(0, \frac{1}{t\|A\|^{2}}\right), 0<\lambda \leq 1$.

Theorem 3.2. Assume that $0<s \leq \frac{1}{2}$ and $0<\liminf _{k \rightarrow \infty} \gamma_{k} \leq \limsup _{k \rightarrow \infty} \gamma_{k}<\frac{1}{t\|A\|^{2}}$. Then the sequence $\left\{x_{k}\right\}$ generated by Algorithm 3.1 weakly converges to a solution $x^{*}$ of MSCFP(1.5). Moreover, $\| x_{k+1}-$ $x_{k} \| \rightarrow 0$ and $\left\|A x_{k+1}-A x_{k}\right\| \rightarrow 0$ as $k \rightarrow \infty$.

Proof. Firstly, we show that $\lim _{k \rightarrow \infty}\left\|x_{k}-x^{*}\right\|$ exists for any $x^{*} \in \Gamma$. Taking $x^{*} \in \Gamma$, we have $x^{*} \in$ $\bigcap_{i=1}^{p} F\left(U_{i}\right)$ and $A x^{*} \in \bigcap_{j=1}^{r} F\left(T_{j}\right)$. For $1 \leq i \leq p$ and $1 \leq j \leq r$, as $U_{i}$ and $T_{j}$ are $s_{i}$-averaged operators and $t_{j}$-averaged operators, respectively, it follows from Lemma 2.9 that $I-U_{i}$ and $I-T_{j}$ are $\frac{1}{2 s_{i}}$-ism and $\frac{1}{2 t_{j}}$-ism, respectively. Thus, from Algorithm 3.1, we have

$$
\begin{aligned}
\left\|v_{k+1}\right\|^{2} & =\left\|\left(I-U_{i(k)}\right)\left(y_{k}+(1-\lambda) v_{k}\right)-\left(I-U_{i(k)}\right) x^{*}\right\|^{2} \\
& \leq 2 s_{i}\left\langle\left(I-U_{i(k)}\right)\left(y_{k}+(1-\lambda) v_{k}\right), y_{k}-x^{*}+(1-\lambda) v_{k}\right\rangle \\
& \leq 2 s\left\langle v_{k+1}, y_{k}-x^{*}+(1-\lambda) v_{k}\right\rangle
\end{aligned}
$$

and

$$
\begin{aligned}
\left\|x_{k+1}-x^{*}\right\|^{2} & =\left\|y_{k}-\lambda v_{k+1}-x^{*}\right\|^{2} \\
& =\left\|y_{k}-x^{*}\right\|^{2}-2 \lambda\left\langle y_{k}-x^{*}, v_{k+1}\right\rangle+\lambda^{2}\left\|v_{k+1}\right\|^{2} .
\end{aligned}
$$


Then we can get

$$
\begin{aligned}
& \left\|x_{k+1}-x^{*}\right\|^{2}+\lambda\left\|v_{k+1}\right\|^{2} \\
= & \left\|y_{k}-x^{*}\right\|^{2}-2 \lambda\left\langle y_{k}-x^{*}, v_{k+1}\right\rangle+\lambda^{2}\left\|v_{k+1}\right\|^{2}+\lambda\left\|v_{k+1}\right\|^{2} \\
= & \left\|y_{k}-x^{*}\right\|^{2}-2 \lambda\left\langle y_{k}-x^{*}, v_{k+1}\right\rangle+\frac{\lambda}{s}\left\|v_{k+1}\right\|^{2}-\lambda\left(\frac{1}{s}-1-\lambda\right)\left\|v_{k+1}\right\|^{2} \\
\leq & \left\|y_{k}-x^{*}\right\|^{2}-2 \lambda\left\langle y_{k}-x^{*}, v_{k+1}\right\rangle+2 \lambda\left\langle y_{k}-x^{*}+(1-\lambda) v_{k}, v_{k+1}\right\rangle-\lambda\left(\frac{1}{s}-1-\lambda\right)\left\|v_{k+1}\right\|^{2} \\
= & \left\|y_{k}-x^{*}\right\|^{2}+2 \lambda(1-\lambda)\left\langle v_{k}, v_{k+1}\right\rangle-\lambda\left(\frac{1}{s}-1-\lambda\right)\left\|v_{k+1}\right\|^{2} .
\end{aligned}
$$

Since

$$
\lambda(1-\lambda)\left\|v_{k+1}-v_{k}\right\|^{2}=\lambda(1-\lambda)\left(\left\|v_{k+1}\right\|^{2}-2\left\langle v_{k+1}, v_{k}\right\rangle+\left\|v_{k}\right\|^{2}\right),
$$

we obtain

$$
\begin{aligned}
& \left\|x_{k+1}-x^{*}\right\|^{2}+\lambda\left\|v_{k+1}\right\|^{2} \\
\leq & \left\|y_{k}-x^{*}\right\|^{2}+\lambda(1-\lambda)\left\|v_{k}\right\|^{2}-\lambda(1-\lambda)\left\|v_{k+1}-v_{k}\right\|^{2}-\lambda\left(\frac{1}{s}-2\right)\left\|v_{k+1}\right\|^{2} .
\end{aligned}
$$

Since

$$
\begin{aligned}
\left\langle x_{k}-x^{*}, A^{*}\left(I-T_{j(k)}\right) A x_{k}\right\rangle & =\left\langle A x_{k}-A x^{*},\left(I-T_{j(k)}\right) A x_{k}-\left(I-T_{j(k)}\right) A x^{*}\right\rangle \\
& \geq \frac{1}{2 t_{j(k)}}\left\|\left(I-T_{j(k)}\right) A x_{k}-\left(I-T_{j(k)}\right) A x^{*}\right\|^{2} \\
& \geq \frac{1}{2 t}\left\|\left(I-T_{j(k)}\right) A x_{k}\right\|^{2},
\end{aligned}
$$

we have

$$
\begin{aligned}
& \left\|y_{k}-x^{*}\right\|^{2} \\
= & \left\|x_{k}-\gamma_{k} A^{*}\left(I-T_{j(k)}\right) A x_{k}-x^{*}\right\|^{2} \\
\leq & \left\|x_{k}-x^{*}\right\|^{2}-2 \gamma_{k}\left\langle x_{k}-x^{*}, A^{*}\left(I-T_{j(k)}\right) A x_{k}\right\rangle+\gamma_{k}^{2}\|A\|^{2}\left\|\left(I-T_{j(k)}\right) A x_{k}\right\|^{2} \\
\leq & \left\|x_{k}-x^{*}\right\|^{2}-\frac{\gamma_{k}}{t}\left\|\left(I-T_{j(k)}\right) A x_{k}\right\|^{2}+\gamma_{k}^{2}\|A\|^{2}\left\|\left(I-T_{j(k)}\right) A x_{k}\right\|^{2} \\
= & \left\|x_{k}-x^{*}\right\|^{2}-\gamma_{k}\left(\frac{1}{t}-\gamma_{k}\|A\|^{2}\right)\left\|\left(I-T_{j(k)}\right) A x_{k}\right\|^{2} .
\end{aligned}
$$

From (3.6) and (3.8), we obtain

$$
\begin{aligned}
& \left\|x_{k+1}-x^{*}\right\|^{2}+\lambda\left\|v_{k+1}\right\|^{2} \\
\leq & \left\|x_{k}-x^{*}\right\|^{2}-\gamma_{k}\left(\frac{1}{t}-\gamma_{k}\|A\|^{2}\right)\left\|\left(I-T_{j(k)}\right) A x_{k}\right\|^{2}+\lambda(1-\lambda)\left\|v_{k}\right\|^{2} \\
& -\lambda(1-\lambda)\left\|v_{k+1}-v_{k}\right\|^{2}-\lambda\left(\frac{1}{s}-2\right)\left\|v_{k+1}\right\|^{2} \\
= & \left\|x_{k}-x^{*}\right\|^{2}+\lambda\left\|v_{k}\right\|^{2}-\gamma_{k}\left(\frac{1}{t}-\gamma_{k}\|A\|^{2}\right)\left\|\left(I-T_{j(k)}\right) A x_{k}\right\|^{2}-\lambda^{2}\left\|v_{k}\right\|^{2} \\
& -\lambda(1-\lambda)\left\|v_{k+1}-v_{k}\right\|^{2}-\lambda\left(\frac{1}{s}-2\right)\left\|v_{k+1}\right\|^{2} .
\end{aligned}
$$

Let $c_{k}=\left\|x_{k}-x^{*}\right\|^{2}+\lambda\left\|v_{k}\right\|^{2}$. By the assumptions on $\left\{\gamma_{k}\right\}, \lambda$, s, and from (3.9), we can get $c_{k+1} \leq c_{k}$. That is the sequence $\left\{c_{k}\right\}$ is non-increasing and lower bounded by 0 , so $\lim _{k \rightarrow \infty} c_{k}$ exists. Then we can 
get $\left\{c_{k}\right\}$ is bounded and hence $\left\{x_{k}\right\}$ is bounded. Moreover, from (3.9), we also have

$$
\gamma_{k}\left(\frac{1}{t}-\gamma_{k}\|A\|^{2}\right)\left\|\left(I-T_{j(k)}\right) A x_{k}\right\|^{2}+\lambda^{2}\left\|v_{k}\right\|^{2} \leq c_{k}-c_{k+1},
$$

which implies that

$$
\lim _{k \rightarrow \infty}\left\|\left(I-T_{j(k)}\right) A x_{k}\right\|=0
$$

and

$$
\lim _{k \rightarrow \infty}\left\|v_{k}\right\|=0 .
$$

So $\lim _{k \rightarrow \infty}\left\|x_{k}-x^{*}\right\|^{2}=\lim _{k \rightarrow \infty}\left(c_{k}-\lambda\left\|v_{k}\right\|^{2}\right)=\lim _{k \rightarrow \infty} c_{k}$ exists. By using Algorithm 3.1 and (3.10), we have

$$
\lim _{k \rightarrow \infty}\left\|x_{k}-y_{k}\right\|=\lim _{k \rightarrow \infty} \gamma_{k}\left\|A^{*}\left(I-T_{j(k)}\right) A x_{k}\right\|=0 .
$$

It follows from (3.11), (3.12) and

$$
\begin{aligned}
& \left\|x_{k}-U_{i(k)} x_{k}\right\| \\
= & \left\|x_{k}-y_{k}-(1-\lambda) v_{k}+\left(I-U_{i(k)}\right)\left(y_{k}+(1-\lambda) v_{k}\right)+U_{i(k)}\left(y_{k}+(1-\lambda) v_{k}\right)-U_{i(k)} x_{k}\right\| \\
\leq & \left\|x_{k}-y_{k}-(1-\lambda) v_{k}\right\|+\left\|\left(I-U_{i(k)}\right)\left(y_{k}+(1-\lambda) v_{k}\right)\right\|+\left\|U_{i(k)}\left(y_{k}+(1-\lambda) v_{k}\right)-U_{i(k)} x_{k}\right\| \\
\leq & 2\left\|x_{k}-y_{k}-(1-\lambda) v_{k}\right\|+\left\|\left(I-U_{i(k)}\right)\left(y_{k}+(1-\lambda) v_{k}\right)\right\| \\
\leq & 2\left\|x_{k}-y_{k}\right\|+2(1-\lambda)\left\|v_{k}\right\|+\left\|v_{k+1}\right\|
\end{aligned}
$$

that

$$
\lim _{k \rightarrow \infty}\left\|x_{k}-U_{i(k)} x_{k}\right\|=0
$$

By (3.11) and (3.12), we also have

$$
\lim _{k \rightarrow \infty}\left\|x_{k+1}-x_{k}\right\|=\lim _{k \rightarrow \infty}\left\|y_{k}-\lambda v_{k+1}-x_{k}\right\|=0,
$$

which infers that $\left\{x_{k}\right\}$ is asymptotically regular. Then we have

$$
\lim _{k \rightarrow \infty}\left\|A x_{k+1}-A x_{k}\right\|=0 .
$$

So $\left\{A x_{k}\right\}$ is asymptotically regular.

Next, we prove that $\omega_{w}\left(x_{k}\right) \subseteq \Gamma$. Assume that $\bar{x} \in \omega_{w}\left(x_{k}\right)$, i.e., there exists a subsequence $\left\{x_{k_{l}}\right\}$ of $\left\{x_{k}\right\}$ such that $x_{k_{l}} \rightarrow \bar{x}$, then $A x_{k_{l}} \rightarrow A \bar{x}$. Noting that the pool of indexes is finite and $\left\{x_{k}\right\}$ is asymptotically regular, for any $i \in\{1,2, \cdots, p\}$, we can choose a subsequence $\left\{k_{i_{m}}\right\} \subset\{k\}$ such that $x_{k_{i_{m}}} \rightarrow \bar{x}$ as $m \rightarrow \infty$ and $i\left(k_{i_{m}}\right)=i$ for all $m$. It turns out that

$$
\lim _{m \rightarrow \infty}\left\|\left(I-U_{i}\right) x_{k_{i_{m}}}\right\|=\lim _{m \rightarrow \infty}\left\|\left(I-U_{i\left(k_{i_{m}}\right)}\right) x_{k_{i_{m}}}\right\|=0 .
$$

By the same reason, for any $j \in\{1,2, \cdots, r\}$, we can choose a subsequence $\left\{k_{j_{n}}\right\} \subset\{k\}$ such that $A x_{k_{j_{n}}} \rightarrow$ $A \bar{x}$ as $n \rightarrow \infty$ and $j\left(k_{j_{n}}\right)=j$ for all $n$. It turns out that

$$
\lim _{n \rightarrow \infty}\left\|\left(I-T_{j}\right) A x_{k_{j_{n}}}\right\|=\lim _{n \rightarrow \infty}\left\|\left(I-T_{j\left(k_{j_{n}}\right)}\right) A x_{k_{j_{n}}}\right\|=0 .
$$

It follows from (3.17), (3.18) and Lemma 2.11 that $\bar{x} \in \bigcap_{i=1}^{p} F(U)$ and $A \bar{x} \in \bigcap_{j=1}^{r} F(T)$. So $\bar{x} \in \Gamma$, and hence $\omega_{w}\left(x_{k}\right) \subseteq \Gamma$.

Finally, by Lemma 2.10, we can get $x_{k} \rightarrow x^{*}$, where $x^{*}$ is a solution of the MSCFP (1.5). And by $v_{k} \rightarrow 0$, we have $\left(v_{k}, x_{k}\right) \rightarrow\left(0, x^{*}\right)$ as $k \rightarrow \infty$. 
Now, we give an application of Theorem 3.2 to solve MSFP (1.1). Let $\left\{C_{i}\right\}_{i=1}^{p}$ and $\left\{Q_{j}\right\}_{j=1}^{r}$ are nonempty closed convex subsets of real Hilbert space $H_{1}$ and $H_{2}$, respectively. It is well known that the orthogonal projection operator is firmly nonexpansive, and a firmly nonexpansive operator is $\frac{1}{2}$-averaged. Assume that the solution set $\Phi$ of MSFP (1.1) is nonempty. From Theorem 3.2, we can deduce easily the following results for solving MSFP (1.1).

Corollary 3.3. Let $\left\{\left(v_{k}, x_{k}\right)\right\}$ be the sequence generated by

$$
\left\{\begin{array}{l}
x_{0}, v_{0} \in H_{1} \text { chosen arbitrarily, } \\
y_{k}=x_{k}-\gamma_{k} A^{*}\left(I-P_{Q_{j(k)}}\right) A x_{k}, \\
v_{k+1}=\left(I-P_{C_{i(k)}}\right)\left(y_{k}+(1-\lambda) v_{k}\right), \\
x_{k+1}=y_{k}-\lambda v_{k+1},
\end{array}\right.
$$

where $0<\lambda \leq 1$ and $0<\liminf _{k \rightarrow \infty} \gamma_{k} \leq \limsup _{k \rightarrow \infty} \gamma_{k}<\frac{2}{\|A\|^{2}}$. Then the sequence $\left\{x_{k}\right\}$ weakly converges to a solution $x^{*}$, where $x^{*} \in \Phi$. Moreover, $\left\|x_{k}-x_{k+1}\right\| \rightarrow 0$ and $\left\|A x_{k}-A x_{k+1}\right\| \rightarrow 0$ as $k \rightarrow \infty$.

Remark 3.4. When $\lambda=1$, for solving MSFP (1.1), algorithm (3.19) becomes the following cyclic iterative algorithm:

$$
x_{k+1}=P_{C_{i(k)}}\left(x_{k}-\gamma_{k} A^{*}\left(I-P_{Q_{j(k)}}\right) A x_{k}\right) .
$$

So, Theorem 3.2 extends the related results of Wang and $\mathrm{Xu}$ [31] for solving the MSFP.

\section{THE MIXED CYCLIC AND PARALLEL ITERATIVE ALGORITHMS}

In this section, for solving the MSCFP (1.5) of averaged operators, we introduce two mixed cyclic and parallel iterative algorithms which make full use of the two methods' structure, and prove the corresponding convergence of the mixed iterative algorithms. We go on making use of the assumptions (A1)-(A3) and adopt the following assumption:

(A4) for all $1 \leq i \leq p, 1 \leq j \leq r$, the sequences $\left\{\alpha_{k}^{i}\right\},\left\{\beta_{k}^{j}\right\} \subset[0,1]$ such that $\Sigma_{i=1}^{p} \alpha_{k}^{i}=1$ and $\Sigma_{j=1}^{r} \beta_{k}^{j}=$ $1(\forall k \geq 0)$.

Algorithm 4.1. (Inner cyclic and outer parallel iterative algorithm) Let $x_{0} \in H_{1}, y_{0} \in H_{2}$ be arbitrary. For $k \geq 1$,

$$
\left\{\begin{array}{l}
y_{k}=x_{k}-\gamma_{k} A^{*}\left(I-T_{j(k)}\right) A x_{k}, \\
v_{k+1}=\left(I-\sum_{i=1}^{p} \alpha_{k}^{i} U_{i}\right)\left(y_{k}+(1-\lambda) v_{k}\right), \\
x_{k+1}=y_{k}-\lambda v_{k+1}
\end{array}\right.
$$

where $\gamma_{k} \in\left(0, \frac{1}{t\|A\|^{2}}\right), 0<\lambda \leq 1$.

Theorem 4.2. Assume that $0<s \leq \frac{1}{2}, 0<\liminf _{k \rightarrow \infty} \gamma_{k} \leq \limsup _{k \rightarrow \infty} \gamma_{k}<\frac{1}{t\|A\|^{2}}$ and $\liminf _{k \rightarrow \infty} \alpha_{k}^{i}>$ $0(1 \leq i \leq p)$. Then the sequence $\left\{x_{k}\right\}$ generated by Algorithm 4.1 weakly converges to a solution $x^{*}$ of the MSCFP (1.5). Moreover, $\left\|x_{k}-x_{k+1}\right\| \rightarrow 0$ and $\left\|A x_{k}-A x_{k+1}\right\| \rightarrow 0$ as $k \rightarrow \infty$.

Proof. Firstly, we show that $\lim _{k \rightarrow \infty}\left\|x_{k}-x^{*}\right\|$ exists for any $x^{*} \in \Gamma$. Taking $x^{*} \in \Gamma$, we have $x^{*} \in$ $\bigcap_{i=1}^{p} F\left(U_{i}\right)$ and $A x^{*} \in \bigcap_{j=1}^{r} F\left(T_{j}\right)$. For $1 \leq i \leq p$ and $1 \leq j \leq r$, as $U_{i}$ and $T_{j}$ are $s_{i}$-averaged operator and $t_{j}$-averaged operator, respectively, by Lemma 2.9, it follows that $I-U_{i}$ and $I-T_{j}$ are $\frac{1}{2 s_{i}}$-ism and 
$\frac{1}{2 t_{j}}$-ism, respectively. Thus, from Algorithm 4.1, we have

$$
\begin{aligned}
\left\|v_{k+1}\right\|^{2}= & \left\|\left[I-\left(\alpha_{k}^{1} U_{1}+\alpha_{k}^{2} U_{2}+\cdots+\alpha_{k}^{p} U_{p}\right)\right]\left(y_{k}+(1-\lambda) v_{k}\right)\right\|^{2} \\
= & \left\|\alpha_{k}^{1}\left(I-U_{1}\right)\left(y_{k}+(1-\lambda) v_{k}\right)+\cdots+\alpha_{k}^{p}\left(I-U_{p}\right)\left(y_{k}+(1-\lambda) v_{k}\right)\right\|^{2} \\
\leq & \alpha_{k}^{1}\left\|\left(I-U_{1}\right)\left(y_{k}+(1-\lambda) v_{k}\right)\right\|^{2}+\cdots+\alpha_{k}^{p}\left\|\left(I-U_{p}\right)\left(y_{k}+(1-\lambda) v_{k}\right)\right\|^{2} \\
= & \alpha_{k}^{1}\left\|\left(I-U_{1}\right)\left(y_{k}+(1-\lambda) v_{k}\right)-\left(I-U_{1}\right) x^{*}\right\|^{2}+\cdots \\
& +\alpha_{k}^{p}\left\|\left(I-U_{p}\right)\left(y_{k}+(1-\lambda) v_{k}\right)-\left(I-U_{p}\right) x^{*}\right\|^{2} \\
\leq & 2 s_{1} \alpha_{k}^{1}\left\langle\left(I-U_{1}\right)\left(y_{k}+(1-\lambda) v_{k}\right), y_{k}-x^{*}+(1-\lambda) v_{k}\right\rangle+\cdots \\
& +2 s_{p} \alpha_{k}^{p}\left\langle\left(I-U_{p}\right)\left(y_{k}+(1-\lambda) v_{k}\right), y_{k}-x^{*}+(1-\lambda) v_{k}\right\rangle \\
\leq & 2 s\left\langle v_{k+1}, y_{k}-x^{*}+(1-\lambda) v_{k}\right\rangle
\end{aligned}
$$

and (3.3) holds. From Theorem 3.2, we get that inequality (3.6) holds, i.e.,

$$
\begin{aligned}
& \left\|x_{k+1}-x^{*}\right\|^{2}+\lambda\left\|v_{k+1}\right\|^{2} \\
\leq & \left\|y_{k}-x^{*}\right\|^{2}+\lambda(1-\lambda)\left\|v_{k}\right\|^{2}-\lambda(1-\lambda)\left\|v_{k+1}-v_{k}\right\|^{2}-\lambda\left(\frac{1}{s}-2\right)\left\|v_{k+1}\right\|^{2} .
\end{aligned}
$$

By the proof of Theorem 3.2, we obtain that inequalities (3.7) and (3.8) hold. So, we can get

$$
\begin{aligned}
& \left\|x_{k+1}-x^{*}\right\|^{2}+\lambda\left\|v_{k+1}\right\|^{2} \\
\leq & \left\|x_{k}-x^{*}\right\|^{2}+\lambda\left\|v_{k}\right\|^{2}-\gamma_{k}\left(\frac{1}{t}-\gamma_{k}\|A\|^{2}\right)\left\|\left(I-T_{j(k)}\right) A x_{k}\right\|^{2}-\lambda^{2}\left\|v_{k}\right\|^{2} \\
& -\lambda(1-\lambda)\left\|v_{k+1}-v_{k}\right\|^{2}-\lambda\left(\frac{1}{s}-2\right)\left\|v_{k+1}\right\|^{2} .
\end{aligned}
$$

Let $c_{k}=\left\|x_{k}-x^{*}\right\|^{2}+\lambda\left\|v_{k}\right\|^{2}$. Similar to the proof of Theorem 3.2, we have

$$
\begin{gathered}
\lim _{k \rightarrow \infty}\left\|\left(I-T_{j(k)}\right) A x_{k}\right\|=0, \\
\lim _{k \rightarrow \infty}\left\|v_{k}\right\|=0
\end{gathered}
$$

and $\lim _{k \rightarrow \infty}\left\|x_{k}-x^{*}\right\|^{2}=\lim _{k \rightarrow \infty} c_{k}$ exists. Then we have that $\left\{x_{k}\right\}$ and $\left\{y_{k}\right\}$ are bounded.

Now, we prove that

$$
\lim _{k \rightarrow \infty}\left\|x_{k}-U_{i} x_{k}\right\|=0
$$

for all $1 \leq i \leq p$. By Algorithm 4.1, we have

$$
\begin{aligned}
\left\|x_{k+1}-x^{*}\right\|^{2} & =\left\|y_{k}-\lambda v_{k+1}-x^{*}\right\|^{2} \\
& =\left\|y_{k}-x^{*}\right\|^{2}-2 \lambda\left\langle v_{k+1}, y_{k}-x^{*}\right\rangle+\lambda^{2}\left\|v_{k+1}\right\|^{2},
\end{aligned}
$$

which implies that

$$
\left\|y_{k}-x^{*}\right\|^{2}=\left\|x_{k+1}-x^{*}\right\|^{2}+2 \lambda\left\langle v_{k+1}, y_{k}-x^{*}\right\rangle-\lambda^{2}\left\|v_{k+1}\right\|^{2} .
$$

It follows from (4.5), the boundedness of $\left\{y_{k}\right\}$ and

$$
\left|\left\langle v_{k+1}, y_{k}-x^{*}\right\rangle\right| \leq\left\|v_{k+1}\right\| \cdot\left\|y_{k}-x^{*}\right\|
$$

that

$$
\lim _{k \rightarrow \infty}\left\|y_{k}-x^{*}\right\|=\lim _{k \rightarrow \infty}\left\|x_{k+1}-x^{*}\right\|=\lim _{k \rightarrow \infty}\left\|x_{k}-x^{*}\right\|
$$


exists. Similarly, from

$$
\left\|y_{k}-\lambda v_{k}-x^{*}\right\|^{2}=\left\|y_{k}-x^{*}\right\|^{2}-2 \lambda\left\langle v_{k}, y_{k}-x^{*}\right\rangle+\lambda^{2}\left\|v_{k}\right\|^{2}
$$

and

$$
\left\|y_{k}+(1-\lambda) v_{k}-x^{*}\right\|^{2}=\left\|y_{k}-x^{*}\right\|^{2}+2(1-\lambda)\left\langle v_{k}, y_{k}-x^{*}\right\rangle+(1-\lambda)^{2}\left\|v_{k}\right\|^{2},
$$

we get

$$
\lim _{k \rightarrow \infty}\left\|y_{k}-\lambda v_{k}-x^{*}\right\|=\lim _{k \rightarrow \infty}\left\|y_{k}+(1-\lambda) v_{k}-x^{*}\right\|=\lim _{k \rightarrow \infty}\left\|x_{k+1}-x^{*}\right\| .
$$

On the other hand, we have

$$
\begin{aligned}
x_{k+1} & =y_{k}-\lambda v_{k+1} \\
& =y_{k}-\lambda\left[y_{k}+(1-\lambda) v_{k}-\sum_{i=1}^{p} \alpha_{k}^{i} U_{i}\left(y_{k}+(1-\lambda) v_{k}\right)\right] \\
& =(1-\lambda) y_{k}-\lambda(1-\lambda) v_{k}+\lambda \sum_{i=1}^{p} \alpha_{k}^{i} U_{i}\left(y_{k}+(1-\lambda) v_{k}\right) \\
& =(1-\lambda)\left(y_{k}-\lambda v_{k}\right)+\lambda \sum_{i=1}^{p} \alpha_{k}^{i} U_{i}\left(y_{k}+(1-\lambda) v_{k}\right) .
\end{aligned}
$$

It follows from (4.11) and Remark 2.3 that

$$
\begin{aligned}
& \left\|x_{k+1}-x^{*}\right\|^{2} \\
\leq & (1-\lambda)\left\|y_{k}-\lambda v_{k}-x^{*}\right\|^{2}+\lambda\left\|\sum_{i=1}^{p} \alpha_{k}^{i} U_{i}\left(y_{k}+(1-\lambda) v_{k}\right)-x^{*}\right\|^{2} \\
\leq & (1-\lambda)\left\|y_{k}-\lambda v_{k}-x^{*}\right\|^{2}+\lambda \sum_{i=1}^{p} \alpha_{k}^{i}\left\|U_{i}\left(y_{k}+(1-\lambda) v_{k}\right)-x^{*}\right\|^{2} \\
\leq & (1-\lambda)\left\|y_{k}-\lambda v_{k}-x^{*}\right\|^{2} \\
& +\lambda \sum_{i=1}^{p} \alpha_{k}^{i}\left(\left\|y_{k}+(1-\lambda) v_{k}-x^{*}\right\|^{2}-\frac{1-s_{i}}{s_{i}}\left\|\left(I-U_{i}\right)\left(y_{k}+(1-\lambda) v_{k}\right)\right\|^{2}\right) \\
\leq & (1-\lambda)\left\|y_{k}-\lambda v_{k}-x^{*}\right\|^{2}+\lambda\left\|y_{k}+(1-\lambda) v_{k}-x^{*}\right\|^{2} \\
& -\frac{\lambda(1-s)}{s} \sum_{i=1}^{p} \alpha_{k}^{i}\left\|\left(I-U_{i}\right)\left(y_{k}+(1-\lambda) v_{k}\right)\right\|^{2},
\end{aligned}
$$

which implies that

$$
\begin{aligned}
& \frac{\lambda(1-s)}{s} \sum_{i=1}^{p} \alpha_{k}^{i}\left\|\left(I-U_{i}\right)\left(y_{k}+(1-\lambda) v_{k}\right)\right\|^{2} \\
\leq & (1-\lambda)\left\|y_{k}-\lambda v_{k}-x^{*}\right\|^{2}+\lambda\left\|y_{k}+(1-\lambda) v_{k}-x^{*}\right\|^{2}-\left\|x_{k+1}-x^{*}\right\|^{2} .
\end{aligned}
$$

From (4.10), (4.13) and the conditions on $\left\{\alpha_{k}^{i}\right\}(1 \leq i \leq p)$, we have

$$
\lim _{k \rightarrow \infty}\left\|\left(I-U_{i}\right)\left(y_{k}+(1-\lambda) v_{k}\right)\right\|=0
$$

for all $1 \leq i \leq p$. By Algorithm 4.1, we have

$$
\left\|x_{k}-y_{k}\right\| \leq\left|\gamma_{k}\right| \cdot\|A\| \cdot\left\|\left(I-T_{j(k)}\right) A x_{k}\right\| .
$$

It follows from (4.4) that

$$
\lim _{k \rightarrow \infty}\left\|x_{k}-y_{k}\right\|=0 .
$$


From

$$
\begin{aligned}
& \left\|x_{k}-U_{i} x_{k}\right\| \\
= & \left\|x_{k}-y_{k}-(1-\lambda) v_{k}+\left(I-U_{i}\right)\left(y_{k}+(1-\lambda) v_{k}\right)+U_{i}\left(y_{k}+(1-\lambda) v_{k}\right)-U_{i} x_{k}\right\| \\
\leq & \left\|x_{k}-y_{k}-(1-\lambda) v_{k}\right\|+\left\|\left(I-U_{i}\right)\left(y_{k}+(1-\lambda) v_{k}\right)\right\|+\left\|U_{i}\left(y_{k}+(1-\lambda) v_{k}\right)-U_{i} x_{k}\right\| \\
\leq & 2\left\|x_{k}-y_{k}-(1-\lambda) v_{k}\right\|+\left\|\left(I-U_{i}\right)\left(y_{k}+(1-\lambda) v_{k}\right)\right\| \\
\leq & 2\left\|x_{k}-y_{k}\right\|+2\left\|(1-\lambda) v_{k}\right\|+\left\|\left(I-U_{i}\right)\left(y_{k}+(1-\lambda) v_{k}\right)\right\|,
\end{aligned}
$$

combining (4.5), (4.14) and (4.16), we can get

$$
\lim _{k \rightarrow \infty}\left\|x_{k}-U_{i} x_{k}\right\|=0
$$

for all $1 \leq i \leq p$. It follows from (4.5), (4.16) and

$$
\left\|x_{k+1}-x_{k}\right\|=\left\|y_{k}-\lambda v_{k+1}-x_{k}\right\| \leq\left\|y_{k}-x_{k}\right\|+\lambda\left\|v_{k+1}\right\|
$$

that

$$
\lim _{k \rightarrow \infty}\left\|x_{k+1}-x_{k}\right\|=0 .
$$

So, $\left\{x_{k}\right\}$ is asymptotically regular. Then we have

$$
\lim _{k \rightarrow \infty}\left\|A x_{k+1}-A x_{k}\right\|=0,
$$

which infers that $\left\{A x_{k}\right\}$ is asymptotically regular.

Next, we prove that $\omega_{w}\left(x_{k}\right) \subseteq \Gamma$. Assume that $\bar{x} \in \omega_{w}\left(x_{k}\right)$, i.e., there exists a subsequence $\left\{x_{k_{l}}\right\}$ of $\left\{x_{k}\right\}$ such that $x_{k_{l}} \rightarrow \bar{x}$, then $A x_{k_{l}} \rightarrow A \bar{x}$. It follows from (4.18) and Lemma 2.11 that $\bar{x} \in \bigcap_{i=1}^{p} F\left(U_{i}\right)$. Since the pool $\{1,2, \cdots, r\}$ is finite, by the same reason of Theorem 3.2, we have $A \bar{x} \in \bigcap_{j=1}^{r} F\left(T_{j}\right)$. So $\bar{x} \in \Gamma$, and hence $\omega_{w}\left(x_{k}\right) \subseteq \Gamma$. By Lemma 2.10, we can get $x_{k} \rightarrow x^{*}$, and hence $\left(v_{k}, x_{k}\right) \rightarrow\left(0, x^{*}\right)$, where $x^{*} \in \Gamma$.

Next, we propose another mixed cyclic and parallel iterative algorithm for solving the MSCFP (1.5) of averaged operators.

Algorithm 4.3. (Inner parallel and outer cyclic iterative algorithm) Let $x_{0} \in H_{1}, y_{0} \in H_{2}$ be arbitrary. For $k \geq 1$,

$$
\left\{\begin{array}{l}
y_{k}=x_{k}-\gamma_{k} \sum_{j=1}^{r} \beta_{k}^{j} A^{*}\left(I-T_{j}\right) A x_{k}, \\
v_{k+1}=\left(I-U_{i(k)}\right)\left(y_{k}+(1-\lambda) v_{k}\right), \\
x_{k+1}=y_{k}-\lambda v_{k+1},
\end{array}\right.
$$

where $\gamma_{k} \in\left(0, \frac{1}{t\|A\|^{2}}\right), 0<\lambda \leq 1$.

Theorem 4.4. Assume that $0<s \leq \frac{1}{2}, 0<\liminf _{k \rightarrow \infty} \gamma_{k} \leq \limsup _{k \rightarrow \infty} \gamma_{k}<\frac{1}{t\|A\|^{2}}$ and $\liminf _{k \rightarrow \infty} \beta_{k}^{j}>$ $0(1 \leq j \leq r)$. Then the sequence $\left\{x_{k}\right\}$ generated by Algorithm 4.3 weakly converges to a solution $x^{*}$ of $\operatorname{MSCFP}$ (1.5). Moreover, $\left\|x_{k}-x_{k+1}\right\| \rightarrow 0$ and $\left\|A x_{k}-A x_{k+1}\right\| \rightarrow 0$ as $k \rightarrow \infty$.

Proof. Taking $x^{*} \in \Gamma$, by the same reason of Theorem 3.2, we know (3.6) holds. Since, for all $1 \leq j \leq r$,

$$
\begin{aligned}
\left\langle x_{k}-x^{*}, A^{*}\left(I-T_{j}\right) A x_{k}\right\rangle & =\left\langle A x_{k}-A x^{*},\left(I-T_{j}\right) A x_{k}-\left(I-T_{j}\right) A x^{*}\right\rangle \\
& \geq \frac{1}{2 t_{j}}\left\|\left(I-T_{j}\right) A x_{k}-\left(I-T_{j}\right) A x^{*}\right\|^{2} \\
& \geq \frac{1}{2 t}\left\|\left(I-T_{j}\right) A x_{k}\right\|^{2},
\end{aligned}
$$


we have

$$
\begin{aligned}
& \left\|y_{k}-x^{*}\right\|^{2} \\
= & \left\|x_{k}-\gamma_{k} \sum_{j=1}^{r} \beta_{k}^{j} A^{*}\left(I-T_{j}\right) A x_{k}-x^{*}\right\|^{2} \\
= & \left\|x_{k}-x^{*}\right\|^{2}-2 \gamma_{k}\left\langle x_{k}-x^{*}, \sum_{j=1}^{r} \beta_{k}^{j} A^{*}\left(I-T_{j}\right) A x_{k}\right\rangle+\gamma_{k}^{2}\left\|\sum_{j=1}^{r} \beta_{k}^{j} A^{*}\left(I-T_{j}\right) A x_{k}\right\|^{2} \\
\leq & \left\|x_{k}-x^{*}\right\|^{2}-2 \gamma_{k} \sum_{j=1}^{r} \beta_{k}^{j}\left\langle x_{k}-x^{*}, A^{*}\left(I-T_{j}\right) A x_{k}\right\rangle+\gamma_{k}^{2} \sum_{j=1}^{r} \beta_{k}^{j}\left\|A^{*}\left(I-T_{j}\right) A x_{k}\right\|^{2} \\
\leq & \left\|x_{k}-x^{*}\right\|^{2}-\frac{\gamma_{k}}{t} \sum_{j=1}^{r} \beta_{k}^{j}\left\|\left(I-T_{j}\right) A x_{k}\right\|^{2}+\gamma_{k}^{2}\|A\|^{2}\left(\sum_{j=1}^{r} \beta_{k}^{j}\left\|\left(I-T_{j}\right) A x_{k}\right\|^{2}\right) \\
= & \left\|x_{k}-x^{*}\right\|^{2}-\gamma_{k}\left(\frac{1}{t}-\gamma_{k}\|A\|^{2}\right)\left(\sum_{j=1}^{r} \beta_{k}^{j}\left\|\left(I-T_{j}\right) A x_{k}\right\|^{2}\right) .
\end{aligned}
$$

It follows from (3.6) and (4.21) that

$$
\begin{aligned}
& \left\|x_{k+1}-x^{*}\right\|^{2}+\lambda\left\|v_{k+1}\right\|^{2} \\
\leq & \left\|x_{k}-x^{*}\right\|^{2}-\gamma_{k}\left(\frac{1}{t}-\gamma_{k}\|A\|^{2}\right)\left(\sum_{j=1}^{r} \beta_{k}^{j}\left\|\left(I-T_{j}\right) A x_{k}\right\|^{2}\right) \\
& +\lambda(1-\lambda)\left\|v_{k}\right\|^{2}-\lambda(1-\lambda)\left\|v_{k+1}-v_{k}\right\|^{2}-\lambda\left(\frac{1}{s}-2\right)\left\|v_{k+1}\right\|^{2} \\
= & \left\|x_{k}-x^{*}\right\|^{2}+\lambda\left\|v_{k}\right\|^{2}-\gamma_{k}\left(\frac{1}{t}-\gamma_{k}\|A\|^{2}\right)\left(\sum_{j=1}^{r} \beta_{k}^{j}\left\|\left(I-T_{j}\right) A x_{k}\right\|^{2}\right) \\
& -\lambda^{2}\left\|v_{k}\right\|^{2}-\lambda(1-\lambda)\left\|v_{k+1}-v_{k}\right\|^{2}-\lambda\left(\frac{1}{s}-2\right)\left\|v_{k+1}\right\|^{2} .
\end{aligned}
$$

Similar to the proof of Theorem 3.2, we have

$$
\lim _{k \rightarrow \infty} \sum_{j=1}^{r} \beta_{k}^{j}\left\|\left(I-T_{j}\right) A x_{k}\right\|^{2}=\lim _{k \rightarrow \infty}\left\|v_{k}\right\|=0,
$$

which implies that

$$
\lim _{k \rightarrow \infty}\left\|\left(I-T_{j}\right) A x_{k}\right\|=0
$$

for all $1 \leq j \leq r$. And we can get $\lim _{k \rightarrow \infty}\left\|x_{k}-x^{*}\right\|^{2}$ exists. By the same proof of Theorem 3.2, we have $\omega_{w}\left(x_{k}\right) \subseteq \Gamma$ and $x_{k} \rightarrow x^{*}$, where $x^{*}$ is a solution of MSCFP (1.5).

Finally, similar to Corollary 3.3 we obtain two mixed iterative algorithms to solve MSFP (1.1). Assume that the solution set $\Phi$ of MSFP (1.1) is nonempty.

Corollary 4.5. For any given $x_{0} \in H_{1}, v_{0} \in H_{2}$, define a sequence $\left\{\left(v_{k}, x_{k}\right)\right\}$ by the following procedure

$$
\left\{\begin{array}{l}
y_{k}=x_{k}-\gamma_{k} A^{*}\left(I-P_{Q_{j(k)}}\right) A x_{k}, \\
v_{k+1}=\left(I-\sum_{i=1}^{p} \alpha_{k}^{i} P_{C_{i}}\right)\left(y_{k}+(1-\lambda) v_{k}\right), \\
x_{k+1}=y_{k}-\lambda v_{k+1},
\end{array}\right.
$$

where $0<\lambda \leq 1,0<\liminf _{k \rightarrow \infty} \gamma_{k} \leq \limsup _{k \rightarrow \infty} \gamma_{k}<\frac{2}{\|A\|^{2}}$ and $\liminf _{k \rightarrow \infty} \alpha_{k}^{i}>0(1 \leq i \leq p)$. Then the sequence $\left\{x_{k}\right\}$ weakly converges to a solution $x^{*} \in \Phi$. Moreover, $\left\|x_{k}-x_{k+1}\right\| \rightarrow 0$ and $\left\|A x_{k}-A x_{k+1}\right\| \rightarrow 0$ as $k \rightarrow \infty$. 
Corollary 4.6. For any given $x_{0} \in H_{1}, v_{0} \in H_{2}$, define a sequence $\left\{\left(v_{k}, x_{k}\right)\right\}$ by the following procedure

$$
\left\{\begin{array}{l}
y_{k}=x_{k}-\gamma_{k} \sum_{j=1}^{r} \beta_{k}^{j} A^{*}\left(I-P_{Q_{j}}\right) A x_{k}, \\
v_{k+1}=\left(I-P_{C_{i(k)}}\right)\left(y_{k}+(1-\lambda) v_{k}\right), \\
x_{k+1}=y_{k}-\lambda v_{k+1},
\end{array}\right.
$$

where $0<\lambda \leq 1,0<\liminf _{k \rightarrow \infty} \gamma_{k} \leq \limsup _{k \rightarrow \infty} \gamma_{k}<\frac{2}{\|A\|^{2}}$ and $\liminf _{k \rightarrow \infty} \beta_{k}^{j}>0(1 \leq j \leq r)$. Then the sequence $\left\{x_{k}\right\}$ weakly converges to a solution $x^{*} \in \Phi$. Moreover, $\left\|x_{k}-x_{k+1}\right\| \rightarrow 0$ and $\left\|A x_{k}-A x_{k+1}\right\| \rightarrow 0$ as $k \rightarrow \infty$.

Remark 4.7. When $\lambda=1$, for solving MSFP (1.1), algorithms (4.23) and (4.24) become the following mixed cyclic and parallel iterative algorithm:

$$
x_{k+1}=\sum_{i=1}^{p} \alpha_{k}^{i} P_{C_{i}}\left(x_{k}-\gamma_{k} A^{*}\left(I-P_{Q_{j(k)}}\right) A x_{k}\right)
$$

and

$$
x_{k+1}=P_{C_{i(k)}}\left(x_{k}-\gamma_{k} \sum_{j=1}^{r} \beta_{k}^{j} A^{*}\left(I-P_{Q_{j}}\right) A x_{k}\right) .
$$

So, Theorem 4.2 and Theorem 4.4 extend the related results of Tang and Liu [32] (Corollary 4.3 and 4.4) for solving the MSFP.

\section{Funding}

This paper was supported by the National Natural Science Foundation of China (No. 61571441) and Scientific Research Project of Tianjin Municipal Education Commission (No. 2018KJ253).

\section{REFERENCES}

[1] Y. Censor, T. Elfving, N. Kopf, T. Bortfeld, The multiple-sets split feasibility problem and its applications for inverse problems, Inverse Probl. 21 (2005), 2071-2084.

[2] P.L. Combettes, The convex feasibility problem in image recovery, Adv. Imaging Electron Phys. 95 (1996), $155-270$.

[3] Y. Censor, T. Bortfeld, B. Martin, A. Trofimov, A unified approach for inversion problems in intensity- modulated radiation therapy, Phys. Med. Biol. 51 (2006), 2353-2365.

[4] Y. Censor, A.B. Israel, Y. Xiao, J.M. Galvin, On linear infeasibility arising in intensity-modulated radiation therapy inverse planning, Linear Algebra. Appl. 428 (2008), 1406-1420.

[5] Y. Censor, T. Elfving, A multiprojection algorithm using Bregman projections in a product space, Numerical Algo. 8 (1994), 221-239.

[6] H.K. Xu, Iterative methods for the split feasibility problem in infinite-dimensional Hilbert spaces, Inverse Probl. 26 (2010), Article ID 105018.

[7] X. Qin, L. Wang, A fixed point method for solving a split feasibility problem in Hilbert spaces, RACSAM Rev. R. Acad. Cienc. Exactas Fis. Nat. Ser. A Mat. 113 (2019), 315-325.

[8] H.H. Bauschke, J.M. Borwein, On projection algorithms for solving convex feasibility problem, SIAM Rev. 38 (1996), 367-426.

[9] L. Liu, A hybrid steepest descent methods for solving split feasibility problems involving nonexpansive mappings, J. Nonlinear Convex Anal. 20 (2019), 471-488.

[10] E. Masad, S. Reich, A note on the multiple-set split convex feasibility problem in Hilbert space, J. Nonlinear Convex Anal. 8 (2007), 367-371.

[11] X. Qin, J.C. Yao, A viscosity iterative method for a split feasibility problem, J. Nonlinear Convex Anal. 20 (2019), 14971506. 
[12] X. Qin, A. Petrusel, J.C. Yao, CQ iterative algorithms for fixed points of nonexpansive mappings and split feasibility problems in Hilbert spaces, J. Nonlinear Convex Anal. 19 (2018), 157-165.

[13] B. Qu, N. Xiu, A note on the CQ algorithm for the split feasibility problem, Inverse Probl. 21 (2005), 1655-1665.

[14] H. Zhou, P. Wang, Adaptively relaxed algorithms for solving the split feasibility problem with a new step size, J. Inequalities Appl. 2014 (2014), Article ID 448.

[15] C. Byrne, Iterative oblique projection onto convex subsets and the split feasibility problem, Inverse Probl. 18 (2002), 441-453.

[16] C. Byrne, A unified treatment of some iterative algorithms in signal processing and image reconstruction, Inverse Probl. 20 (2004), 103-120.

[17] Y. Censor, A. Segal, The split common fixed point problem for directed operators, J. Convex Anal. 16 (2009), 587-600.

[18] A. Cegielski, General method for solving the split common fixed point problem, J. Optim. Theory Appl. 165 (2015), 385-404.

[19] H. Cui, F. Wang, Iterative methods for the split commom fixed point problem in Hilbert spaces, Fixed Point Theory Appl. 2014 (2014), 78.

[20] A. Moudafi, A note on the split common fixed point problem for quasi-nonexpansive operators, Nonlinear Anal. 74 (2011), 4083-4087.

[21] J. Zhao, S. He, Viscosity approximation methods for split common fixed-point problem of directed operators, Numer. Funct. Anal. Optim. 36 (2015), 528-547.

[22] Y. Censor, A. Gibali, S. Reich, Algorithms for the split variational inequality problem, Numer. Algor. 59 (2012), $301-323$.

[23] M. Eslamian, G.Z. Eskandani, M. Raeisi, Split common null point and common fixed point problems between Banach spaces and Hilbert spaces, Mediterr. J. Math. 14 (2017), Article ID 119.

[24] A. Moudafi, The split common fixed point problem for demicontractive mappings, Inverse Probl. 26 (2010), Article ID 055007.

[25] Y.C. Tang, J.G. Peng, L.W. Liu, A cyclic algorithm for the split common fixed point problem of demicontractive mappings in Hilbert Spaces, Math. Model. Anal. 17 (2012), 457-466.

[26] M. Wen, J. Peng, Y. Tang, A cyclic and simultaneous iterative method for solving the multiple-sets split feasibility problem, J. Optim. Theory Appl. 166 (2015), 844-860.

[27] H.K. Xu, A variable Krasnosel'ski $\breve{i}-M a n n$ algorithm and the multiple-set split feasibility problem, Inverse Probl. 22 (2006), 2021-2034.

[28] Q. Yang, The relaxed CQ algorithm solving the split feasibility problem, Inverse Probl. 20 (2004), 1261-1266.

[29] Y. Yao, Z. Yao, A.A. Abdou, Y.J. Cho, Self-adaptive algorithms for proximal split feasibility problems and strong convergence analysis, Fixed Point Theory Appl. 2015 (2015), Article ID 205.

[30] W. Zhang, D. Han and Z. Li, A self-adaptive projection method for solving the multiple-sets split feasibility problem, Inverse Probl. 25 (2009), Article ID 115001.

[31] F. Wang, H. Xu, Cyclic algorithms for split feasibility problems in Hilbert spaces, Nonlinear Anal. 74 (2011), $4105-4111$.

[32] Y.C. Tang, L.W. Liu, Several iterative algorithms for solving the split common fixed point problem of directed operators with applications, Optimization 65 (2016), 53-65.

[33] P. Chen, J. Huang, X. Zhang, A primal-dual fixed point algorithm for convex separable minimization with applications to image restoration, Inverse Probl. 29 (2013), Article ID 025011.

[34] J. Zhao, H. Zong, Iterative algorithms for solving the split feasibility problem in Hilbert spaces, J. Fixed Point Theory Appl. 20 (2018), Article ID 11.

[35] C. Matinez-Yanes, H.K. Xu, Strong convergence of the CQ method for fixed point processes, Nonlinear Anal. 64 (2006), 2400-2411.

[36] Y. Hao, S.Y. Cho, X. Qin, Some weak convergence theorems for a family of asymptotically nonexpansive nonself mappings, Fixed Point Theory Appl. 2010 (2010), Article ID 218573.

[37] H.H. Bauschke, The approximation of fixed points of composition of nonexpansive mappings in Hilbert space, J. Math. Anal. Appl. 202 (1996), 150-159. 